\title{
Los fugitivos escondidos: acerca del enigma tapiete
}

Les fugitifs cachés : à propos de l'énigme tapiete

Hidden Fugitives: Regarding the Tapiete Enigma

\section{Isabelle Combès}

\section{OpenEdition}

Journals

Edición electrónica

URL: http://journals.openedition.org/bifea/2996

DOI: $10.4000 /$ bifea.2996

ISSN: 2076-5827

\section{Editor}

Institut Français d'Études Andines

\section{Edición impresa}

Fecha de publicación: 1 diciembre 2008

Paginación: 511-533

ISSN: 0303-7495

\section{Referencia electrónica}

Isabelle Combès, "Los fugitivos escondidos: acerca del enigma tapiete », Bulletin de l'Institut français d'études andines [En línea], 37 (3) | 2008, Publicado el 01 junio 2009, consultado el 27 noviembre 2020. URL : http://journals.openedition.org/bifea/2996 ; DOI : https://doi.org/10.4000/bifea.2996

Les contenus du Bulletin de l'Institut français d'études andines sont mis à disposition selon les termes de la licence Creative Commons Attribution - Pas d'Utilisation Commerciale - Pas de Modification 4.0 International. 


\title{
Los fugitivos escondidos: acerca del enigma tapiete
}

\author{
Isabelle Combès*
}

\section{Resumen}

Porque hablan guaraní pero poseen una cultura netamente chaqueña, los tapietes representaron siempre una irritante enigma para los antropólogos, que vieron en ellos grupos chaqueños guaranizados o, a la inversa, grupos guaraníes chaqueñizados. Se propone aquí una relectura de las fuentes etnohistóricas sobre el Chaco, para sugerir una guaranización «en dos tiempos» de grupos chaqueños, y eso desde el siglo XVI, por intermediario de grupos chanés que habían fugado hacia el Chaco. La conclusión sugiere que el caso tapiete es paradigmático de toda la dinámica étnica chaqueña y de su periferia, que las nuevas investigaciones deben volver a pensar, con nuevas herramientas conceptuales o teóricas.

Palabras clave: tapiete, chané, chiriguano, Chaco, etnohistoria, etnogénesis

\section{Les fugitifs cachés : à propos de l'énigme tapiete}

\section{Résumé}

Parce qu'ils parlent guarani mais possèdent une culture qui appartient nettement au Chaco, les Tapiete ont toujours posé une énigme agaçante aux anthropologues, qui ont vu en eux des groupes du Chaco guaranisés ou, au contraire, des groupes guarani «chaquénisés». L'article propose une relecture des sources ethnohistoriques sur le Chaco, pour suggérer une guaranisation « en deux temps » d'ethnies du Chaco, ce dès le XVI ${ }^{\text {ème }}$ siècle, par l'intermédiaire de groupes chané qui s'étaient réfugiés dans le Chaco. La conclusion suggère que le cas des Tapiete est paradigmatique de toute la dynamique ethnique du Chaco et de sa périphérie qu'il convient de repenser avec de nouveaux outils conceptuels ou théoriques.

Mots clés : Tapiete, Chané, Chiriguano, ethnohistoire, ethnogénèse.

Instituto Francés de Estudios Andinos/UMIFRE 17 CNRS-MAEE. E-mail: kunhati@gmail.com

Agradezco a Jean-Pierre Estival por sus informaciones sobre los tapietes de Paraguay, a Kathleen Lowrey, Diego

Villar y Frederica Barclay y a Nicolás Richard por las largas discusiones sobre la Babel chaqueña. 


\title{
Hidden Fugitives: Regarding the Tapiete Enigma
}

\begin{abstract}
The Tapieté have always represented something of an anthropological enigma because they speak Guaraní but lead a culturally Chacoan way of life. Anthropologists have alternatively proposed that they are either a «Guaranized» population of Chacoan origin or, inversely, a «Chaqueñized» population of immigrant Guaraní. The present essay suggests a re-reading of ethnohistorial sources pertaining to the Chaco and argues for a guaranization «in two epochs» of some Chacoan groups. This process would have begun in the sixteenth century and been carried out via intermediaries: Chané groups, themselves previously guaranized, forced by colonial-era dynamics to flee from their homelands into the relatively inhospitable Chaco. The essay concludes that the case of the Tapiete is paradigmatic of the broader dynamic of ethnogenesis in the Chaco and its periphery, a dynamic that remains to be reconceptualized in new investigations by emerging analytic tools and theories.
\end{abstract}

Key words: Tapiete, Chané, Chiriguano, ethnohistory, ethnogenesis

\section{PERO PARECE, PERO CURIOSAMENTE...}

Ocho comunidades en el departamento de Boquerón en Paraguay, que reunirían a 1351 personas; una aldea en el Chaco boliviano con 43 personas, a las cuales tendríamos que agregar como cien más, dispersas en las localidades cercanas; dos comunidades en el norte argentino, con algo más de 1500 habitantes: en total, son unas 3000 personas las que constituyen el grupo étnico del Chaco conocido bajo el nombre de «tapiete»1.

Empleado por los antropólogos, pero también por otros grupos indígenas como los chiriguanos, el término de «tapiete» hoy constituye una auto-denominación en Bolivia y en el norte argentino; pero no goza de tal aceptación en Paraguay, donde la gente prefiere llamarse ñandereta («nosotros») o bien, cuando se trata de relacionarse con el gobierno o las organizaciones de desarrollo, «guaraní ñandeva». Esta proliferación de nombres no es, como veremos, el menor de los problemas que plantean «los tapietes» a los antropólogos.

Ñandereta o ñandeva, los nombres elegidos hoy en Paraguay son —como «tapiete» además- nombres guaraníes: nada muy extraño, pues la etnia habla efectivamente una lengua guaraní, bastante próxima al guaraní chiriguano hablado en Bolivia y en el norte argentino. Sin embargo, precisamente en este punto surge lo que Mario Califano (1978) definió como «el enigma» tapiete, uno de los rompecabezas más complejos de la etnografía y la historia chaqueñas. Algunos testimonios bastarán para plantear los términos del problema:

[Los tapietes] hablan la lengua chiriguana [...] algunas de sus costumbres son idénticas a las de los chiriguanos; pero parece que tienen otras que han adquirido de los tobas (Cardús, 1886: 269; énfasis mío).

Los tapietes, una tribu típicamente chaqueña, tienen una cultura muy similar a la de los matacos y chorotis, pero, curiosamente, hablan el dialecto guaraní de sus vecinos chiriguanos (Métraux, 1946: 238; énfasis mío)².

1 Cifras proporcionadas por Arce et al. (2003: 72) e Hirsch (2006: cap. 2).

2 Todas las traducciones al castellano son mías. 
Verdadera Biblia de los estudios chaqueños, el Indianerleben («La vida de los indios») dedica su penúltimo capítulo a los tapietes. El primer párrafo de este capítulo reza así:

«He descrito hasta aquí dos culturas indígenas diferentes, la que hemos conocido entre los choroti y ashluslay que todavía son primitivos, y la que hemos encontrado al pie de los Andes, de los chanés y chiriguanos medio civilizados. Los indios sobre los que quiero informar ahora, son interesantes por el hecho que tienen la cultura material de los primeros y el idioma de estos últimos (guaraní)》 (Nordenskiöld, 2002 [1912]: 276; énfasis mío).

Más allá de los prejuicios y juicios de valor explícitos en este párrafo, Nordenskiöld plantea cabalmente las premisas del rompecabezas: por una parte, los tapietes hablan un idioma guaraní próximo al guaraní chiriguano ${ }^{3}$. Comparten además mucho más que la lengua con los chiriguanos del piedemonte andino: las fiestas del arete (carnaval), el uso de las máscaras (que no conocen los guaraníes paraguayos) o del violín; los une, también, la importancia simbólica que los «agricultores fracasados», que son los tapietes, dan al cultivo del maíz, la misma importancia que le dan los más exitosos chiriguanos (Estival, 2002). Pero se trata también, por otra parte, de un grupo cuya cultura material pertenece mayoritaria y nítidamente a la «civilización del Chaco» definida por Métraux (1946):

No les conocemos, pues, a los tapietes otro idioma que el guaraní. En cuanto a la cultura pertenecen los tapietes más bien a los matacos, chorotis y tobas, que a los chiriguanos $[\ldots]$ sus herramientas de pesca, en el río Pilcomayo, son las mismas que la de los matacos, tobas y chorotis (...) sus tejidos son iguales a los de los chorotis, tobas y matacos (Nordenskiöld, 1910).

Poco más tarde, el mismo autor sostiene que «describir la cultura de los tapietes sería prácticamente una repetición de lo dicho acerca de los chorotis y los ashushlay» (2002 [1912]: 282) —aun si advierte, en la misma página, que si bien las mujeres tapietes «están tatuadas casi a la manera de los choroti», los hombres ostentan, por lo contrario, la tembeta (tarugo labial) de los chiriguanos-.

Hay que notarlo, los dos aspectos de la cultura tapiete no se reducen a una oposición simplista entre cultura material y lengua. Las danzas, otros instrumentos de música aparte del violín, el tipo mismo de chamanismo de los tapietes nos remiten también a la «civilización del Chaco» (J.-P. Estival, com. pers.).

De ahí el «misterio» o la «apasionante incógnita» (Califano, 1978: 169), de ahí la perplejidad y las numerosas migrañas de los antropólogos a la hora de «clasificar» a los tapietes frente a la evidencia: en un caso tan nítidamente híbrido, la tradicional clasificación lingüística no es de gran utilidad. Nordenskiöld fue el primero, en 1910, en plantear el problema e intentar darle solución; pero la tarea no es fácil, y el enigma ha continuado a oponer a los antropólogos entre sí. Numerosas razones — que son como tantos obstáculos a la resolución del misterio- explican las dificultades encontradas.

Tapiete es una palabra guaraní, más exactamente es un superlativo (-ete: «verdadero», «muy», «por excelencia») del término guaraní tapï. Se trata más precisamente de un término que, además de su significado despectivo, fue siempre aplicado por diversos grupos

3 Dietrich (1986) considera el tapiete como un dialecto del chiriguano; otros investigadores, como Hebé González, son menos afirmativos y piensan que las diferencias entre ambos permiten considerar el chiriguano y el tapiete como dos idiomas diferentes — sin embargo próximos, en todo caso más próximos entre sí que con el guaraní paraguayo (Hirsch, 2006)—. 
guaraní-hablantes a otros que no compartían el mismo idioma. El diccionario guaraní de Ruiz de Montoya ofrece, en 1640, esta definición:

«tapiiî: generación, esclavo; y assi llama el Guarani á las demás naciones» (1876 [1640]: 355; énfasis mío).

Las referencias no faltan al respecto para los chiriguanos, desde las primeras décadas de la conquista:

Su costumbre destos es andar syempre ala guerra contra las otras generaçiones q no son de su lengua a los cuales todos ellos llaman esclavos (Anónimo, 1941 [c. 1573]: 66).

Tienen todas las naciones en poco e por esclavos (Suárez de Figueroa, 1965 [1586]: 405).

Como los españoles, también tienen brío de conquistar las otras naciones, a las cuales todas llaman esclavos (Barzana, 1965 [1594]: 84).

Es esta gente (...) mui soueruia y así a todos los llama esclavos (Padre Samaniego, fines del siglo XVI, en Crónica anónima, 1944 [c. 1600]: 485).

Es gente superiorísima; todas las naciones dicen ser sus esclavos (Lizárraga, 1968 [c. 1600]: 83).

«A todos» y a «todas las naciones»: esto significa, y es importante subrayarlo, que el nombre de tap̈̈, el nombre de «esclavo», fue aplicado por diversos grupos guaraní-hablantes a etnias o «naciones» totalmente diferentes entre sí. Los «tapouyeste» (tapï-ete) de los tupinambá de Brasil en el siglo XVI eran indios de lengua gé; en la misma época en los llanos del actual oriente boliviano, un grupo chiquito-hablante era llamado «tapuy-miri» («pequeños tapiii») por los guaraníes que acompañaban a los primeros exploradores españoles llegados desde Paraguay — de hecho, este nombre directamente traducido al castellano está al origen del de los indígenas «chiquitos», hoy «chiquitanos»-. En el piedemonte andino de la actual Bolivia, en la «Cordillera chiriguana», tapï era en general el nombre dado a los grupos chanés esclavizados y «guaranizados» por los migrantes guaraní-hablantes llegados desde Paraguay. En general, pero no siempre: como bien lo advierte Susnik (1968: 26), durante la Colonia «con el nombre Tapii identificábase cualquier tribu llanera». A inicios del siglo XX incluso, Nordenskiöld nota que muchos blancos llaman «tapietes» a los ashushlay (nivaklés) del curso inferior del Pilcomayo; los «tapietes» encontrados por la expedición Campos que bajó el Pilcomayo en 1883 no serían otros que los nivaklés (Nordenskiöld, 1910; 2002 [1912]: 25; ver Campos, 1888).

En otras palabras, en el siglo XIX el término de «tapiete» padece la misma suerte que el de yanaigua o ñanaigua, otra palabra guaraní que significa literalmente «los que viven en el bosque» y que se podría traducir, respetando el significado que le dan los chiriguanos, como «salvaje» o «bárbaro». En la zona del Isoso en el siglo XIX, el nombre de yanaigua fue aplicado a la vez a grupos ayoréos (grupo lingüístico zamuco) y a grupos «tapietes» de idioma guaraní (Combès, 2004). Ni tapiete ni yanaigua son «nombres étnicos» y mucho menos auto-denominaciones. Son apodos, despectivos, dados por los guaraní-hablantes (aquí: los chiriguanos) a los grupos vistos como inferiores, incivilizados.

Hoy en el Chaco — paraguayo, boliviano o argentino-, la palabra «tapiete» designa a un solo grupo de personas: pero las líneas que anteceden ilustran bien los problemas que deben enfrentar los investigadores para identificarlo, a su vez, en las fuentes históricas. De hecho, artículos hoy clásicos como los de Schmidt (1937) y Califano (1978) tratan indiferentemente de los tapï y de los tapietes, como si constituyeran un solo grupo étnico identificable; la misma confusión existe en el capítulo histórico del reciente libro de Arce et al. (2003) sobre los tapietes de Bolivia. 
El hecho que el término de tapiete no haya sido jamás —al menos, hasta estos últimos años- una auto-denominación, complica aún más las cosas. González señala que los grupos del Chaco paraguayo rechazan las etiquetas de «tapiete» y de «ñanaigua» que les dan los blancos (1968: 262) y ya mencioné que nuevas denominaciones existen hoy entre los «tapietes» de Paraguay. Por el contrario, en Bolivia se adoptó el nombre como una denominación étnica propia, pero mediante una reinterpretación que borra absolutamente su sentido peyorativo: tap̈̈̈-ete está entendido hoy como «los hombres verdaderos» —interpretación adoptada además por varios investigadores («Tapiete significa gente verdadera» —Carvajal, 1998: 363-); también en Argentina, «para muchos tapietes, la palabra tapï significa hombre y tapiete es una castellanizada del término» (Hirsch, 2006: 24)4.

¿Cómo desenredar entonces la madeja que presentan las fuentes históricas y distinguir entre unos «tapietes» que no lo son (como los nivaklés citados por Nordenskiöld) y otros «tapietes» llamados también yanaigua y cuya auto-denominación primitiva no es conocida? Para complicar aún más el rompecabezas, se debe subrayar también que, en las fuentes históricas sobre el Chaco, el nombre de «tapiete» como nombre aplicado a un solo grupo étnico de idioma guaraní (es decir, a los «tapietes» actuales) no aparece antes del siglo XIX (Susnik, 1968: 191; Combès, 2007). Una última traba, que por última no es menos irritante, concierne precisamente a «las fuentes históricas sobre el Chaco», que son prácticamente inexistentes si nos referimos al corazón mismo de la región. Aparte de los primeros viajes de Juan de Ayolas y Domingo de Irala a través del Chaco en el siglo XVI, aparte de los casi 30 años de vida de la efímera misión jesuita de San Ignacio de Zamucos a mediados del siglo XVIII, aparte de los viajes de Sánchez Labrador a finales del mismo siglo (Sánchez Labrador, 1910 [c. 1767]), las fuentes se refieren en general a la periferia del Chaco —el piedemonte andino y la «Cordillera chiriguana» al oeste, la Chiquitania al norte, las riberas del río Paraguay al este y las del Bermejo al sur-. Silencio total, o casi total, sobre el inmenso territorio comprendido entre estas diferentes fronteras.

\section{2. ¿QUIÉN ACULTURÓ A QUIÉN?}

Para intentar explicar, a pesar de las limitaciones de las fuentes, el «misterio» tapiete, varias hipótesis han sido propuestas; algunas se deben a los «santos patronos» de los estudios chaqueños —Nordenskiöld, Métraux y Susnik-. Se pueden reagrupar estas hipótesis en dos grandes propuestas: la primera ve en los tapietes a un (o unos) grupo(s) chaqueño(s) guaranizado(s); la segunda, por el contrario, hace de ellos unos guaraníes «chaqueñizados».

La primera propuesta es actualmente la más difundida y la más aceptada. Se basa, en particular, en la existencia de un precedente histórico muy bien documentado y muy estudiado, a saber la guaranización sufrida por los grupos chanés (arawak) del piedemonte

4 El hecho no es, además, ni nuevo ni aislado. En el Isoso, región poblada en el siglo XVI por chanés guaranizados que huían de sus amos chiriguanos, tapï significa hoy «hombre», «guaraní», incluso «más guaraní que los chiriguanos»; en el noroeste argentino, los chanés traducen el término por «amigo» o palabras equivalentes. Si bien los chiriguanos prefieren hoy llamarse «guaraníes» para hacer olvidar las interpretaciones despectivas del nombre «chiriguano», los tapï emplearon otra táctica, conservando el nombre pero dándole un significado totalmente opuesto a su significación original. Sobre «las políticas del nombre» y los nuevos etnónimos que pululan en el Chaco desde la guerra entre Paraguay y Bolivia (1932-1935), remito a Richard, s/f; 2008; Combès, $2006 a$. 


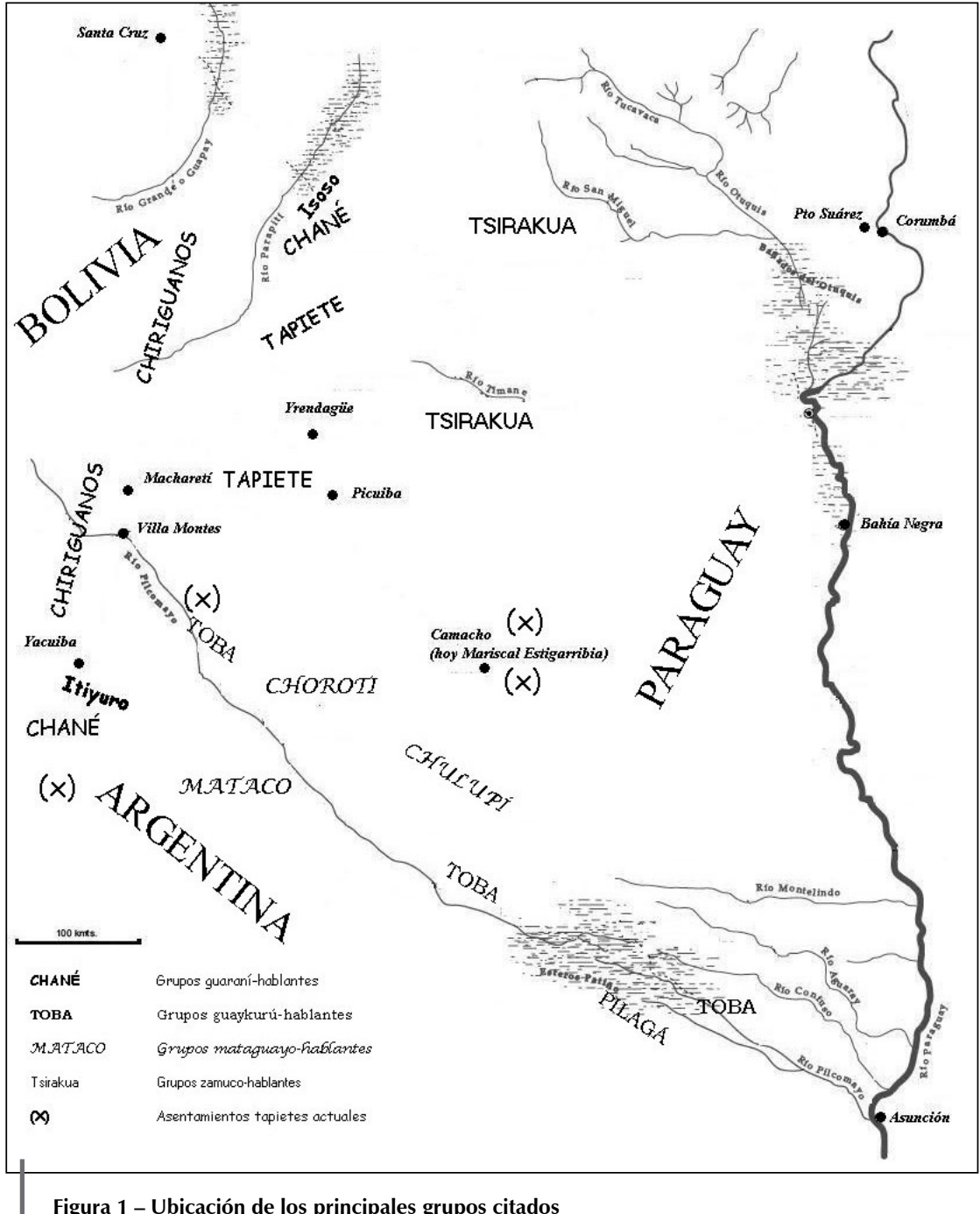

Figura 1 - Ubicación de los principales grupos citados

Los nombres y la ubicación corresponden a inicios del siglo 20; los datos son demasiado escasos para los siglos anteriores. Con $(\mathrm{X})$, se indican los asentamientos tapietes actuales.

Correspondencia de nombres:

Toba, Pilagá: hoy Qom, Toba-pilagá

Tsirakua: hoy Ayoréode

Mataco: hoy Wichí (Argentina), Weenhayek (Bolivia)

Choroti: hoy Manjui

Chulupí (Ashluslay de Nordenskiöld): hoy Nivaklé 
andino en manos de grupos guaraníes llegados desde el este a partir del siglo XV; esta guaranización de los chanés (llamados «tapïi» por los guaraní-hablantes) y el mestizaje que siguió dieron nacimiento a una nueva etnia, la de los actuales chiriguanos (Susnik, 1968; Pifarré, 1989; Combès \& Saignes, 1991). A partir de este ejemplo histórico, se postula entonces que, si los chanés fueron guaranizados y nació así una nueva etnia, lo mismo pudo ocurrir en el Chaco.

Los investigadores han propuesto varios guiones: para Nordenskiöld (1910; 2002 [1912]: cap. 19), Métraux (1946) y Susnik (1968: 191-193; 1989: 461), los tapietes son grupos de idioma mataguayo (matacos, wichí) guaranizados. La opinión de Nordenskiöld es que los tapietes «son una tribu perteneciente al grupo mataco-choroti, que adoptó la lengua guaraní aunque hayan conservado su propia cultura» (2002 [1912]: 281); Susnik (1989: 461) habla de un «ramal proto-mataco ofyenik» guaranizado. En cuanto a Métraux, se basa en particular sobre las indicaciones de Lozano, quien menciona a un cacique mataco llamado Nao que domina perfectamente la lengua guaraní, y señala sobre todo la existencia de un grupo de «mataguayos coronados» que hablan el guaraní, aunque su idioma materno sea otro (Lozano, 1733: 76, 194).

Si bien adoptan la misma tesis de un grupo chaqueño guaranizado, Max Schmidt (1937) y luego Mario Califano (1978) prefieren identificar este grupo como zamuco y no mataguayo. Esta interpretación me parece más frágil que las anteriores. Schmidt se basa, en particular, sobre una dudosa identificación entre el grupo de los tamacocis que vivía en el siglo XVI a orillas del río Grande a la altura de la actual ciudad de Santa Cruz en Bolivia, y los zamucos. Esta identificación se funda sobre la grafía de «samocosi» empleada por Ruy Díaz de Guzmán en su Argentina (1835 [1612]: 82, 134). Numerosas fuentes indican, sin ninguna ambigüedad, que los tamacocis fueron sometidos en el siglo XVI, y tal vez antes, por los chiriguanos, a los cuales rendían por ejemplo tributos (Combès \& Hirtzel, 2007). El razonamiento de Schmidt es entonces el siguiente: los tamacocis fueron sometidos por los chiriguanos y entonces probablemente guaranizados por ellos como lo fueron los chanés; los tamacocis son zamucos, ergo, existieron grupos originalmente zamucos y luego guaranizados, y los descendientes de estos grupos son los tapietes. En cuanto a Califano, cita, como un argumento más, al grupo llamado «tapi» presente, a mediados del siglo XVIII, en la misión jesuita de San Ignacio de Zamucos. Estos «tapi» zamucos constituyen, para el autor, una confirmación de la hipótesis que ve en los tapi-etes un grupo de lengua zamuca posteriormente guaranizado. Estos argumentos me parecen frágiles por varias razones: primero, Díaz de Guzmán es el único autor quien utiliza la grafía de «samocosi» para designar al grupo que todos los demás cronistas nombran tamacoci; estos otros cronistas son, además, conquistadores del siglo XVI como Irala, Ñuflo de Chávez, Schmidel, etc., quienes conocieron de visu a los tamacocis, mientras Díaz de Guzmán escribe de oídas y algunas décadas después. Más importante, recientes investigaciones parecen mostrar, sin mucho riesgo de equivocación, que los tamacocis eran en realidad un grupo de habla chané, es decir arawak (Combès \& Hirtzel, 2007). Tercero, los «tapi» de San Ignacio son probablemente los tapios o sapios mencionados por Chomé, misionero de Zamucos (1791 [1738]): desaparece en este caso la similitud de los nombres, y con ella una relación con los tapietes. Finalmente, la cultura material entera de los actuales tapietes pertenece a la «civilización del Chaco» así bautizada por Métraux; y es un hecho que la cultura de los ayoréos e ishir (chamacocos) actuales, únicos representantes del grupo lingüístico zamuco, no pertenece a este conjunto cultural - aunque solo fuera por la existencia de clanes y mitades, desconocidos de los grupos «típicamente» chaqueños como los chorotis, nivaklés y demás tobas-. 
Propuse recientemente otra interpretación —que pretendo profundizar y matizar en estas líneas- del «misterio tapiete» (Combès, 2007). Tomando en cuenta las numerosas referencias que mencionan, a inicios del siglo XIX, a los «chanés y mataguayos» de la región del Itiyuro en el noroeste argentino, sugerí que los tapietes podrían ser grupos mataguayos guaranizados en la misma época... pero guaranizados por chanés, por unos tapï que habían adoptado desde siglos el idioma guaraní de los chiriguanos. Mediante esta hipótesis, intentaba explicar, primero, el nombre mismo dado a los tapietes («verdaderos tapï», «más tapit que los tapïi») y, luego, el hecho que el nombre «tapiete» no aparece en las fuentes antes del siglo XIX. Volveré más adelante sobre esta propuesta.

El segundo grupo de hipótesis - a saber, las que consideran por el contrario a los tapietes como a un grupo guaraní chaqueñizado - es mucho menos difundido, y menos aceptado en la literatura antropológica. Tiene en realidad dos versiones algo antitéticas.

Primera versión: cuando ocurrieron las migraciones guaraníes hacia el oeste, varios grupos se habrían quedado en el Chaco, sin alcanzar a llegar al piedemonte andino. Estos grupos se habrían entonces mestizado con etnias chaqueñas, y dado nacimiento a los tapietes. Es, por ejemplo, la opinión de Cardús cuando escribe de los tapietes:

«según dicen, son chiriguanos que cuando emigraban del Paraguay dejaron a los demás, quedándose en donde actualmente están» (1886: 269).

Esta versión es naturalmente plausible, aunque imposible de «probar» o verificar por la ausencia misma de fuentes escritas sobre el interior del Chaco en esta remota época. Solo una nota de Lozano, algo tardía, podría confirmarla. En efecto, al elaborar la lista de las «naciones» que viven «desde el Yaveviry al Sur azia el Pilcomayo», Lozano termina su enumeración de la siguiente manera:

«de allí [i.e. cerca del Pilcomayo] ya empiezan tierras de Chiriguanas, que se quedaron en los Llanos de Manso» (1733: 52; énfasis mío).

Los «llanos de Manso» era, como es sabido, el nombre dado a prácticamente todo el Chaco boreal hasta el siglo XIX5. Ninguna otra fuente menciona a chiriguanos establecidos en pleno corazón del Chaco, y la expresión escogida por Lozano, «que se quedaron», tampoco puede dejar pensar que pueda tratarse, por lo contrario, de chiriguanos replegados en el Chaco desde la Cordillera y el piedemonte andino. Así, los «chiriguanas» de Lozano tal vez sean tapietes...: lo sorprendente es que ninguno de los autores que se preocuparon por el origen de los tapietes haya hecho mención de esta cita, ni siquiera los más modernos como Arce et al. (2003) para quiénes los tapietes son, sin lugar a dudas (pero sin lugar a pruebas tampoco), descendientes de los grupos guaraníes que cruzaron el Chaco6. Sin embargo, en ausencia de más datos, una prudente reserva está de rigor. Ninguna otra fuente confirma el dato proporcionado por Lozano, quien escribe además su monumental Descripción chorográfica del Gran Chaco a partir, generalmente, de cartas de misioneros y no de visu. De hecho, por ejemplo en el caso de los mbayá-guaykurú, un cronista de la talla de Sánchez Labrador no repara en criticar ferozmente a su hermano en religión (Sánchez Labrador, 1910 [c. 1767])7. Más significativo aún, esta hipótesis postula entonces que grupos guaraníes originarios del Paraguay se habrían quedado en el Chaco, sin alcanzar a llegar al

5 Este nombre proviene del conquistador Andrés Manso, quien estableció una efímera colonia entre los chiriguanos del río Parapetí entre 1559 y 1564, antes de ser victimado por ellos.

6 Estos autores se refieren por ejemplo a «la época en que los tupí guaraní (entre ellos los tapietes) llegaron al Chaco...» (Arce et al., 2003: 7; énfasis mío).

7 Ver por ejemplo tomo 1: 261-266. 
piedemonte andino. Sin embargo, el «lado guaraní» de los actuales tapietes —el idioma, el uso de las máscaras, del violín, etc.- es, con toda evidencia, un «lado chiriguano». Como ya mencioné, esta última etnia se formó, en el piedemonte andino, a partir del mestizaje entre guaraníes y chanés. Adoptó un número considerable de aportes chanés, como por ejemplo el uso de las máscaras desconocido de los guaraníes paraguayos8. En otras palabras, y para emplear la expresión consagrada, «todo ocurre como si» el lado guaraní de los tapietes tuviera su origen en el oeste, en el piedemonte andino, en la cultura chiriguana... y este hecho no es compatible con la hipótesis de grupos guaraníes paraguayos que se hubieran quedado varados en el Chaco. Recordemos aquí las palabras de Branislava Susnik, cuando subraya que para identificar el o los grupos que dieron nacimiento a los tapietes, se debe ante todo «considerar la condición esencial: la necesidad de que el supuesto grupo étnico hubiera tenido una estrecha relación subordinada de los Chiriguanos, la de sraza cautiva〉, pues solamente esta circunstancia facultaba antiguamente una «tapiización` social y una guaranización lingüística» (1968: 192).

Segunda versión en juego que considera a los tapietes como unos guaraníes chaqueñizados: se trataría de chiriguanos (o de chanés guaranizados, volveré largamente sobre este punto) quienes habrían huido hacia el Chaco en una época todavía indeterminada, para escapar de los españoles de Charcas o (en el caso de los chanés guaranizados) de los chiriguanos que no solamente los utilizaban como siervos, sino que también los capturaban para venderlos a los españoles. Una vez «Chaco adentro», estos fugitivos no habrían tenido otra opción que mezclarse con los grupos locales y adoptar lo esencial de sus costumbres mejor adaptadas a estas tierras inhóspitas y desconocidas. Hasta donde llega mi conocimiento, Gustavo González (1968) fue el único quien defendió esta hipótesis, que no tuvo eco en los estudios posteriores. Tal vez esto se deba al título mismo del artículo de González: «entre los Guaraní-Chané (o Ñanaguas) del noroeste chaqueño», formulación que no llama precisamente la atención sobre «los tapietes»... eterno problema de la babélica clasificación étnica chaqueña.

\section{DE ARRIBA HACIA ABAJO: LA HIPÓTESIS CHANÉ}

Una vez resumido el estado de la cuestión, ¿qué nuevos datos podemos esperar encontrar para resolver el misterio del origen de los tapietes?

Más o menos sólidas, más o menos convincentes, las hipótesis existentes me parecen todas pecar en un punto: son demasiado unidireccionales. O bien los guaraníes (o los chiriguanos, o los chanés guaranizados) guaranizaron a los chaqueños, o bien, por el contrario, los chaqueños chaqueñizaron a los guaraníes (o a los chiriguanos, o a los chanés guaranizados); en ambos casos, el resultado son los tapietes. Sin embargo es una evidencia: las relaciones interétnicas no son nunca tan simples ni tan unilaterales. En el caso chiriguano, si bien los chanés fueron dominados, si bien adoptaron el idioma de sus amos y gran parte de su sistema religioso, también aportaron, en contraparte, las máscaras, las técnicas de riego, las del tejido, los estilos de cerámica, etc. Y su aporte no se limita, como se pensó por largo tiempo, a la cultura material: la organización política entera de los chiriguanos, con su sistema de «casas» nobles y de rango hereditario, es una herencia chané callada, pero también innegable (Combès \& Villar, 2004; Combès, 2005; Combès \& Lowrey,

8 Fausto (2003) nota la ausencia de máscaras entre los grupos tupí y guaraní hablantes; cuando éstas existen, su presencia se debe a aportes externos (chanés, en el caso chiriguano). 
2006)9. Las palabras, las cosas, las técnicas y las creencias circulan en ambos sentidos y la «guaranización» de los unos va junta con la «chaneización» de los otros — de la misma manera que, en otros casos, se puede hablar tanto de la «tukanoización» o «panoización» de grupos arawak como de la «arawakización» de los tukano o de los pano (Hill \& SantosGranero, 2002; Hornborg, 2005: 607)—. Con toda evidencia, es en un proceso similar que debemos pensar en el caso tapiete.

Debe notarse, luego, otro elemento: existe, entre los chiriguanos, una jerarquía de los «Otros» que bien podría contribuir a echar alguna luz sobre el misterio tapiete. Las observaciones coloniales ya citadas afirman todas que los chiriguanos consideran como «esclavos» a «todas las otras naciones». A menudo, estas mismas observaciones agregan: «salvo a los españoles» (Suárez de Figueroa, 1965 [1586]: 405), o bien: «si no es al español que dize es como ellos, y los llaman cuñados» (Padre Samaniego en Crónica anónima, 1944 [c. 1600]: 485). «Cuñados», es decir tovaya, literalmente «el que está al frente», el enemigo y el cuñado a la vez (ver Clastres, 1972). Los tupinambás de Brasil llamaban así tovaya a los demás grupos tupies de los alrededores. Enemigos, pero semejantes, e iguales. Como lo muestran las citas anteriores, los chiriguanos aplicaron el mismo término a los blancos — aun si, muy rápidamente, se generalizó el de karai en su sentido de «extraordinario, raro, curioso»10—. En otras palabras, al menos dos primeras categorías se perfilan para clasificar a «los otros»: el karai, superior; el tovaya, semejante e igual en estatus.

Aparte de los chiriguanos, ningún otro grupo guaraní-hablante estaba establecido en el piedemonte andino. Si bien los diferentes grupos chiriguanos eran probablemente tovaya entre sí, el único «Otro» que encontraron y podría responder a este criterio era el español. Por el contrario, los chiriguanos sí encontraron a muchos tapï (tapï tout court, tapï-miri, etc.), que son los «esclavos» de las crónicas y, todos, indígenas de otro idioma que el guaraní. Los tapiti son considerados como diferentes, como inferiores sobre todo (de hecho, son a menudo utilizados como esclavos, siervos o peones por los chiriguanos): pero no llegan a ser, en la visión chiriguana, verdaderos «salvajes» — y ahí aparece la última categoría de los «Otros», la de los yanaigua, de los bárbaros que viven en el bosque:

«si bien no son tovaya, es decir iguales, los tap̈̈ no son tampoco «salvajes» como los ñanaigua. Son diferentes de los chiriguanos, son considerados como sus inferiores, pero son más próximos a ellos que los otros grupos nómadas del Chaco» (Combès, 2005: 67).

¿Acaso es una verdadera sorpresa? En este punto también los tapietes plantean un problema: porque son tapï (e incluso: tapï-ete, «verdaderos» tapïi) y también son, al menos en el siglo XIX, yanaigua (Combès, 2004; 2005: cap. 7).

Gustavo González recogió entre los «tapietes» (a quienes llama «guaraní-chané o ñanagua») un mito de origen que explica que, antaño, los tapï (aquí: los tapietes) vivían «arriba» (en los cerros) y los chiriguanos «abajo»; luego, después de disputas y guerras, los tapï tuvieron que irse a vivir «abajo» (es decir, en los llanos) y los chiriguanos «arriba» (1968: 265). La sola

9 Recordemos además que los chanés eran mucho más numerosos que los guaraníes cuando estos últimos llegaron al piedemonte andino (estimaciones en Combès \& Saignes, 1991: 58-59): su supremacía demográfica no puede ser dejada de lado a la hora de evaluar los aportes respectivos de ambos grupos en la cultura chiriguana.

10 Los chiriguanos ya llamaban karai a los blancos en el siglo XVI (Padre Yáñez, 1595. In: Annua, 1965 [1596]: 107). Entre los guaraníes paraguayos, Karai era también el nombre de los «profetas» de los movimientos mesiánicos y el de varios héroes civilizadores; en cambio entre los chiriguanos, no existe ninguna referencia a personajes míticos llamados Karai, y los «hombres-dioses» eran denominados tumpa. 
existencia de este relato es, de paso, un dato más que prueba las relaciones mantenidas por este grupo con los chiriguanos del piedemonte más que con hipotéticos grupos guaraníes paraguayos varados en pleno Chaco.

Otros recogieron el mismo mito, o casi, a la vez entre los chanés guaranizados del Isoso y entre los chiriguanos. Los chanés del Isoso contaron a Nordenskiöld que vivían antaño río Parapetí arriba, pero que luego fueron expulsados «por un gran jefe» hacia el río abajo (Nordenskiöld, 2002 [1912]: 156). Una historia parecida es la que cuenta el Diccionario chiriguano-español del padre franciscano Giannecchini, en el artículo «Tapîi». Al contarla, Giannecchini reúne en una sola categoría a los tapietes y los chanés:

«Tapîi, s. Tapiete, chanés. Etog. Así llamaban los indios paraguayos à todas las otras naciones que tenían alrededor, y que no pertenecían á la propia. Nuestros chiriguanos llaman así á la sola tribu de los tapietes o chaneses. Historia. Cuenta la tradición indo-chiriguana que antiguamente los tapîi formaban una sola tribu con los chiriguanos, como lo indica el mismo idioma y costumbres que poseen con muy poca diferencia. Los primeros vivían hacia los cerros y los segúndos en los campos. Sucediò que por desavenencia interna se declararon guerra unos a otros, en la que los abajeños vencieron, desbarataron y cautivaron a los arribeños y desde entonces los llamaron tapîi, que en guaraní quiere decir cautivo» (Giannecchini et al., 1916: 198; énfasis mío).

Según Gustavo González, estos relatos podrían corresponder a recuerdos de las antiguas migraciones guaraníes llegadas desde el este a través del Chaco (desde «abajo») hasta el piedemonte andino («arriba»), expulsando así a numerosos habitantes (chanés) de la Cordillera (de arriba) hacia el Chaco (hacia abajo). Esta interpretación me parece totalmente pertinente y válida; las fuentes coloniales la confirman además absolutamente. Hablando de los «naturales de los Ilanos», Juan de Matienzo escribe:

«Estos pobres yndios viendo la crueldad de los chiriguanaes y el mal que les hazian huyeron del gran temor que les tenian y desampararon su propia tierra que eran vnos muy buenos y fertiles valles (...) en que los mismos chiriguanaes se han quedado y se fueron a vnos llanos y arenales que solian estar despoblados adonde no ay agua sino a treinta estados y la que hallan es muy poca y en muy pocas partes beben del zumo de los cardones y de yucas son muchos en quantidad mas de cient mill segund fama» (Matienzo, 1922 [1561]: 54).

Otros testimonios contemporáneos agregan:

«Estos indios eran naturales de los valles que están a los principios de la cordillera que poseen los Chiriguanas (...) echados de [la región de] los Chiriguanas, se pasaron en aquella asperesa de tierra por escapar de sus crueldades» (Relación atribuida a Ruy González Maldonado, 1965 [c. 1564]: 398-399).

«[Los chiriguanos] echaron a los naturales de los llanos de los lugares que tenían y donde beuian y auitaban y de miedo sullo se recogieron a los llanos tierra des[es] perada y enferma e donde no ay agua» (Audiencia de Charcas, 1922 [1566]: 442).

De la misma manera, a inicios del siglo XVII, el capitán Diego de Contreras, procurador general de la ciudad de La Plata (actual Sucre), alude a los «Indios Chanes que se han huydo» y viven en unos «desiertos adonde estan escondidos de miedo de los Chiriguanas» ${ }^{11}$. Algunos años más tarde, aprovechando la llegada del conquistador Ruy Díaz de Guzmán a 
Macharetí, «más de dos mill» chanés huyen «a los llanos [...] con el temor y amenazas de los dichos Chiriguanas que tiranicamente los tienen tan sujetos» (Díaz de Guzmán, 1979 [1618]: 98-99).

Estos chanés que huyen de los chiriguanos, en forma a veces masiva, son en su inmensa mayoría chanés ya guaranizados al menos lingüísticamente, que han sido víctimas de la esclavitud en las aldeas chiriguanas y buscan, precisamente, su libertad. Varios se establecieron, a mitades del siglo XVI, en el Isoso donde Nordenskiöld encontraría siglos más tarde a sus descendientes y donde siguen viviendo hoy (Combès, 2005: cap. 2 y 3 y passim). ¿Y los demás? Aún sin tomar al pie de la letra a los «más de cient mill» de Matienzo, los numerosos testimonios coloniales deben hacernos pensar en cantidades considerables de fugitivos. Con toda evidencia, no todos se quedaron en el Isoso — la región no podía bastar para satisfacer sus necesidades-. Las fuentes nos indican su destino: «aquella asperesa de tierra», «los llanos tierra des[es]perada y enferma e donde no ay agua» -es decir los «llanos de Manso», es decir el Chaco boreal-. Lo confirma, además, el relato que hicieron los isoseños a Nordenskiöld a inicios del siglo XX:

«Los chané del río Parapetí me dijeron que primero habían vivido en el curso superior de este río, pero que fueron expulsados por un gran jefe. Algunos se quedaron donde viven ahora [i.e.: en el Isoso], otros atravesaron el Chaco hacia el río Paraguay» (Nordenskiöld, 2002 [1912]: 156; énfasis mío).

Existe incluso un término para designarles: tap̈̈ ñemi (ñemi: «oculto, escondido»), que González traduce como «esclavo fugitivo, escondido» (1968: 264) y Giannecchini como «cautivos fugados, escondidos» (Giannecchini et al., 1916: 198). El mismo diccionario considera a los «tapîiñemi» como a una «parcialidad de tapietes» y explica que formaban «antiguamente con los tapîi una sola tribu, sujeta a los chiriguanos». Habiéndose rebelado contra los chiriguanos, estos últimos los capturaron para sacrificar y comerlos:

«Mas habiendo los presos barruntado lo que les iba a pasar, se fugaron [...] huyendo por lo más espeso del monte para no ser alcanzados ni hallados por sus crueles amos [...] Así los prófugos se independizaron y desaparecieron de toda sociedad hasta el presente» (Giannecchini et al., 1916: 198).

En el mismo artículo de su indispensable diccionario, el franciscano indica que los tapï ñemi son a veces llamados itirubói, es decir itirumbae, «sin tiru», siendo el tiru la túnica tradicional chiriguana (Giannecchini et al., 1916: 199). Itirumbae es un término prácticamente sinónimo de yanaigua, de «salvaje», que fue a menudo traducido casi literalmente como «empelotos» (en pelotas) por los blancos; es también, por supuesto, un término tan genérico como tapii, como tapiete o como yanaigua, que pudo ser aplicado por los chiriguanos a grupos muy diferentes. En otro libro, Giannecchini (1896: 40) explica que los «yanaigua» son a veces llamados tapiñemi y que, según los chiriguanos, se tratarían de ex tapï (es decir, de ex chanés esclavos) destinados al rito caníbal, pero que lograron huir - es la misma historia, exactamente, que la que consigna el Diccionario ChiriguanoEspañol-. En 1868, cuando los «yanaigua» (en este caso: los tapietes stricto sensu) atacan las haciendas criollas del Isoso, un documento habla de ataques de «tapuiñemes» (MHSC FP 2/82-11, 6-05-1868). Por su parte, Nordenskiöld indica que antiguas urnas funerarias probablemente arawak (chané) encontradas en la zona de Tarupayu al sur del Pilcomayo eran atribuidas por los chiriguanos locales a los «itapuiñemi», «que vivían en las alturas mientras que los chiriguanos viven en los valles» (2001 [1924]: 34, 51).

En la actualidad, cuando no existen más grupos «escondidos» en el Chaco y que los «tapietes» viven en comunidades relacionadas con el mundo blanco y con otros indígenas, cambió la significación de tapï ñemi: González indica que para los tapietes paraguayos, se 
trata de un indio fantasma cuyo papel es el del lobo feroz en los cuentos europeos: asustar a los niños; entre los chanés del Itiyuro, los tapï ñemi también pasaron al registro mítico:

«Son personas que viven en cuevas escondidas en las laderas del cerro, andan apenas vestidos y evitan a toda costa ser vistos. Su piel, repleta de cicatrices de raíces y espinas, es extremadamente curtida, y se los describe en consecuencia con epítetos como 〈arisco〉 o 〈salvajè. Por si fuera poco a veces es posible escuchar sus voces, pero hablan un idioma incomprensible, compuesto de silbidos, onomatopeyas y sonidos guturales. Si bien evitan todo contacto, representan un peligro serio para las mujeres que se arriesgan a entrar solas en el monte. Existen de hecho varios relatos de muchachas raptadas por los tapuy ñemi; y en alguno de ellos, cuando tiempo después fueron vistas en el monte por algún pariente, las cautivas se negaron a volver sin emitir palabra, como si hubieran perdido la facultad del lenguaje» (Villar, 2006: 22).

Villar agrega, en la misma página, que «inútil es preguntarse acerca del origen histórico de estos grupos extraños y salvajes» que pertenecen a un registro lingüístico mítico, al contrario de los yanaigua por ejemplo, mencionados siempre en contextos narrativos de historia oral. Sin embargo, cuando los isoseños hablaron de los ataques de los «tapuiñemes» en 1868, no se referían a criaturas míticas, sino a ataques bien concretos de gente también bien concreta. No sería ni la primera ni la última vez que personajes, pueblos o acontecimientos históricos pasan al registro de los cuentos o de los mitos; entre los ayoréos chaqueños, un personaje mítico no sería sino un recuerdo transformado de los jesuitas de San Ignacio de Zamucos (Bernd Fischermann, com. pers.); entre los ishir o chamacocos del Chaco, el mito entero de los «extranjeros furiosos», si bien puede (y debe) ser interpretado en un plano mítico, también puede corresponder a recuerdos históricos reales del encuentro entre los chamacocos y otros grupos indígenas (Richard, 2008: cap. 4): pienso que lo mismo ocurre en el caso de los tapï ñemi, y que una interpretación más «mítica» de lo que representan en la actualidad no excluye otra más histórica como la que propongo aquí.

Para resumir, tenemos entonces la certidumbre de que numerosos chanés (tapï), guaranizados por un ya largo y estrecho contacto con los chiriguanos, huyeron «Chaco adentro», y eso desde el siglo XVI. Sabemos, también, que tanto los «tapietes» como los tapii ñemi han sido llamados yanaigua: de nuevo, «todo ocurre como si» tapietes y tapii ñemi hubieran constituido como una categoría intermediaria entre los tapï tout court y los salvajes yanaigua; como si se les hubiera considerado como gente que participan un poco de ambos - y esto nos remite, por supuesto, a la «doble cara», guaraní (chiriguana) y chaqueña a la vez, de los tapietes-

Mi hipótesis es, entonces, que los «tapietes» (el grupo conocido hoy con este nombre) son el resultado de un largo proceso de mestizaje entre chanés guaranizados que huyeron hacia los llanos, y diversos grupos chaqueños. Por así decirlo, a las hipótesis sugeridas por Nodenskiöld, Métraux y Susnik12, agrego aquí un eslabón intermedio: una guaranización en dos tiempos, la de los chanés primero, la de los grupos chaqueños en contacto con estos chanés luego. Es también el punto esencial que resalto de la hipótesis que sugerí anteriormente (Combès, 2007), aunque yo proponga aquí otras circunstancias, y otras épocas más remotas, para la guaranización de los grupos chaqueños.

12 Hay que notar las intuiciones de Susnik cuando escribía: «diversos eran los grupos étnicos que pasaron por este proceso [de esclavitud y guaranización] y algunos llegaron a fugarse y retirarse a las tierras inhóspitas del Chaco; el P. Giannecchini refiere la tradición de los tapìi-ñemi, los «tapì escondidos», fugitivos de la antigua condición de servidumbre a los amos 〈ava〉 [chiriguanos]» (1968: 192). Sin embargo, la autora no relacionó a estos tapï ñemi con los mismos chanés fugitivos. 
Esta conclusión es importante, pues acaso permita entender por qué los tapietes actuales no son «tan» guaraní como lo son los chanés por ejemplo del Isoso o del Itiyuro, productos de una primera ola de guaranización y que estuvieron siempre en contacto más o menos cercano con los chiriguanos. Estos chanés son «más chanés» que los que se integraron directamente a las comunidades chiriguanas y se «hicieron chiriguanos»... pero son también «más guaraníes» que los tapietes producto de una segunda ola de guaranización y quienes, desde el corazón del Chaco, tuvieron mucho menos contactos directos con los chiriguanos, cuando sí los tenían a diario con los grupos chaqueños circundantes con quiénes se casaron. Es un hecho, los tapietes actuales son «más chaqueños» que «guaraníes», y la frecuencia de sus matrimonios con miembros de otros grupos chaqueños también va en este sentido. La hipótesis histórica aquí propuesta puede permitir, en mi criterio, entender este estado de hecho.

\section{LOS TAPIETES}

Si bien el «origen» de los tapietes puede leerse en la huida de los esclavos chanés hacia el Chaco, la historia no se acaba ahí. De hecho, es más que probable que los grupos tapietes hayan recibido otros aportes, sustanciales, desde la cordillera chiriguana, particularmente en la segunda mitad del siglo XIX cuando son esta vez chiriguanos los que huyen Chaco adentro para huir de las misiones franciscanas en algunos casos y más a menudo de los colonos blancos.

El ejemplo más expresivo es sin duda el de Kayuguari. Según Nino (1912: 71, 96, 121), Kayuguari era un chiriguano de Macharetí quien salió hacia el Chaco en 1856 ó 1857, porque no estaba de acuerdo con el jefe Mandepora acerca del establecimiento de una misión franciscana en la comunidad. Sanabria cuenta la misma historia, pero sitúa la salida de Kayuguari en 1892, después de la famosa batalla de Kuruyuki que perdieron los chiriguanos frente al ejército republicano (Sanabria, 1972; 1988 [1958]: 258). La información de Nino es aparentemente la más correcta, pues cinco años antes de Kuruyuki, en 1887, el padre Giannecchini ya menciona al «famoso ladrón» Kayuguari (1896: 196). En 1908 todavía, Nordenskiöld recogió noticias del personaje:

«en las tierras indómitas del Chaco sigue viviendo el jefe chiriguano Cayuhuari en cuya aldea no ha estado ningún hombre blanco» (2002 [1912]: 150).

El campamento principal de Kayuguari era Kumbarurenda a 30 leguas al norte del río Pilcomayo - en pleno territorio tapiete, como lo indica el diario de Giannecchini (1896: 196, 203 n. 1). El campamento comprendía «una plazuelita con cinco ranchitos, según la arquitectura chiriguana, y dos toldos á la de los Tobas» (Giannecchini, 1896: 196). Mucho más tarde, en 1927, el mayor Ángel Ayoroa recorre «los campos de Cayuguari» —-todavía conocidos bajo este nombre, aunque Kayuguari mismo ya haya muerto- al sureste del Isoso, también en pleno territorio tapiete (Ayoroa, 1927: 515-516, 519).

Analicé en otra parte los ataques dirigidos por Kayuguari en contra de las haciendas del Isoso en los años 1892 y 1893 (Combès, 2004; 2005: cap. 7). En este afán, el «famoso ladrón» había reunido un verdadero ejército multiétnico compuesto de tobas, tapietes, matacos, chorotes y algunos chiriguanos (MHSC FP 3/126, 12-04-1892). En 1893, estaba acompañado por varios jefes llamados Cototo, Cura («el Cura»), Aragüira y Tiripi (MHSC FP 3/129, 24-03-1893). Más tarde, Nino confirma la información: los asaltos de Kayuguari se hacen «en compañía de tobas, tapietés y otras tribus» (1912: 96) - y no son pocos los informes que hablan, directamente, de «los kayuguari» como de un solo grupo. Años después, según Nordenskiöld, Kayuguari habría encontrado refugio entre los tobas argentinos (2002 [1912]: 150). 
Chiriguanos, tapietes, tobas, matacos y chorotes: una vez más, y esta vez sin el intermediario de los chanés, se juntan pueblos que representan «los dos lados» de la cultura tapiete. Los intercambios y las alianzas del fin del siglo XIX solo pudieron contribuir a remodelarla, o afirmarla. El jefe Cototo que acompaña a Kayuguari en 1893 lo hace junto con un tal Borevireza [Mboreviresa: «ojo de tapir»] que Giannecchini (1896: 179) identifica como un jefe tapiete; este Cototo es tal vez el mismo chiriguano quien, 20 años antes, había huido de la misión de San Francisco del Pilcomayo para encontrar refugio entre los tobas donde contrajo matrimonio (Giannecchini, 1988 [1879]: 330, 332-333); más que probablemente, se trata también del mismo personaje que el explorador Thouar califica directamente de «toba» en 188713: resulta bien difícil «clasificar» a este personaje, ya no chiriguano y pariente político de los tobas... un rompecabezas muy parecido al que plantea la «clasificación» de los tapietes.

En 1892, después del fracaso de la batalla de Kuruyuki y de las feroces represalias blancas, numerosos chiriguanos «se dispersaron por los bosques» (Martarelli \& Nino, 2006 [1918]: 144); muchos encontraron refugio en el Chaco: en 1895, Manuel Othon Jofré, delegado del gobierno boliviano, nota que la colonia militar Crévaux, a orillas del Pilcomayo, «se encuentra rodeada de tribus salvajes [...] Las tribus principales son de tobas, tapietes, chorotes, noctenes y chiriguanos, de los que se sublevaron en el Azero14» (2006 [1895]: 519-520). Una de las aldeas citadas por Jofré es Yanduñanca, que el padre franciscano Pifferi describe, el mismo año, como un rancho de tobas, «tapietes, chorotis y no pocos chiriguanos de los que sobrevivieron a la última guerra de Curuyuqui» (citado por Arce et al., 2003: 19). Como lo subraya González (1968: 266), es muy plausible que estos chiriguanos fugitivos se volvieron a encontrar en el Chaco con los tapietes, que tenían sobre los tobas y demás chorotes la ventaja de hablar su mismo idioma.

Los sucesivos aportes que contribuyeron a moldear la actual cultura tapiete no se reducen, por supuesto, a los aportes Ilegados desde la Cordillera chiriguana: las coaliciones del siglo XIX, ya evocadas, estrecharon los lazos ya fuertes que unían a los tapietes con los chaqueños; contribuyó también a este acercamiento, con seguridad, la paulatina colonización del río Pilcomayo a la vez desde Bolivia y Argentina, que incrementó el número y la fuerza de las coaliciones, e incitaron a menudo a los grupos de las orillas del río a buscar refugio en el interior de las tierras, al norte del río, es decir en territorio tapiete.

Estos casos, que no son aislados, significan que no debemos pensar en un solo y único acontecimiento que habría «creado», prácticamente de una vez por todas, a los tapietes. Se trata, por el contrario, de un proceso largo y complejo, dinámico y cambiante también, que comenzó ya en el siglo XVI con las fugas a veces masivas de los esclavos chanés, y se acentuó luego. Los «chiriguanas» de los llanos de Manso mencionados por Lozano son muy probablemente «tapietes», grupos — e insisto sobre el plural— de chanés guaranizados que se escaparon para vivir en el Chaco y con los chaqueños. Nuevos aportes tuvieron lugar poco a poco, según las circunstancias. El mismo Lozano (1733: 333) indica que para escapar de las represalias blancas que siguieron la rebelión de Aruma en 1729 al sur del Pilcomayo, numerosos chiriguanos huyeron «azia la parte de los Tobas inmediatos», es decir hacia el Chaco, como lo harían un siglo y medio después de la batalla de Kuruyuki. Otros aportes tuvieron probablemente lugar a finales del siglo XVIII, cuando los chanés guaranizados de Sanandita al sur del Pilcomayo conquistaron su independencia gracias a una alianza con los grupos tobas y matacos más occidentales (Combès, 2007). Entre los aportes chiriguanos

13 ANB PL 286, Boletín del ministerio de relaciones esteriores y colonización, 1887, $\mathrm{n}^{\circ} 7$ (1-10): 9.

${ }^{14}$ Es decir la provincia Azero o Acero, donde se ubicaba Kuruyuki. 
o chanés a la cultura tapiete figura el violín, que los primeros conocieron en las misiones franciscanas iniciadas recién en 1758. Luego, como lo vimos, la segunda mitad del siglo XIX aportó también su contingente de nuevos contactos ya sea con los chiriguanos o con los chaqueños.

Así, debemos pensar en unos grupos tapietes y no en una «etnia» en el sentido clásico y a menudo demasiado monolítico. Unos grupos probablemente mestizados con gente diferente según las épocas y las circunstancias —los unos más con matacos, los otros más con chorotes, etc.- - Los tapietes contemporáneos se casan «lejos», como lo muestran los datos etnográficos y las estadísticas - pero, casi siempre, con sus antiguos socios chaqueños: entre los tapietes de Samuwate en Bolivia, «más del 80 \% de las unidades domésticas son matrimonios cruzados o entreverados» (Arce et al., 2003: 57) y el mismo autor señala otros casos numerosos de matrimonios mixtos entre los tapietes paraguayos (2003: 120, ss) —; exceptuando algunos matrimonios con blancos, los conyugues preferenciales pertenecen todos a grupos chaqueños como los wichí o matacos, los nivaklés, chorotes o tobas. En la comunidad tapiete de Tartagal en Argentina, Silvia Hirsch advierte frecuentes matrimonios entre tapietes y chorotes y agrega haber encontrado a «muchas parejas de ancianos cuyos conyugues tenían distintos orígenes étnicos [...] Actualmente la mayoría de los matrimonios de la comunidad son interétnicos» (Hirsch, 2006: 133)15. Los relatos de los exploradores del Pilcomayo en la segunda mitad del siglo XIX testimonian, a su manera, de una situación parecida. Dos hijos del jefe chorote Yasuru acompañan, en 1863, al jefe toba Iñiri (Gianelli, 1988 [1863]: 295); la aldea toba de Cabayurepoti (nombre dado por los chiriguanos) es, en 1883, el «cuartel general donde se reúnen gran parte de las tribus del Norte del Chaco para deliberar en negocios de defensa común, paz o guerra» (Campos, 1888: 104). Los tapietes, parte integrante del incesante juego de alianzas y guerras entre los grupos chaqueños, son muy probablemente también los socios de los intercambios matrimoniales interétnicos. Unos tapietes entonces, grupos acaso enemigos entre sí, con alianzas cambiantes: una «nación» tal vez en un sentido cultural, pero en ningún caso en un sentido político —al menos hasta una época muy reciente e influenciada por los movimientos indígenas y las organizaciones de desarrollo que los aconsejan-.

En el siglo XIX, más particularmente en la segunda mitad de ese siglo, los colonos blancos avanzan cada vez más hacia el Chaco, desde el oeste (Sucre, Tarija), el norte (Santa Cruz) y el sur (Argentina); colonizan el Isoso, bajan el Pilcomayo. Si bien la situación provoca, como mencioné, significativas huidas de chiriguanos hacia los llanos, también implica un contacto más directo, sea forzoso o voluntario, de los tapietes (de algunos grupos tapietes) con los blancos y/o con otros indígenas. En otras palabras, en esta época, algunos grupos tapietes salen del Chaco, los «escondidos» se dejan ver. Aparecen en coaliciones guerreras, a veces junto con los chiriguanos (Kayuguari), otras veces (o al mismo tiempo) con grupos chaqueños; asaltan las haciendas del Isoso. Pero también se incorporan, en mayor o menor medida, en las comunidades tapï del Isoso (Combès, 2004; 2005: 191, 244) y en las aldeas chiriguanas del noroeste argentino. Ahí, reencontrándose de alguna manera con su pasado de «esclavos», trabajan como peones para los indígenas de estas comunidades a cambio, generalmente, de maíz:

«no es nada extraño que [los tapietes] trabajen para [los chiriguanos] como sirvientes. También he visto trabajar a los tapietes para los chanés» (Nordenskiöld, 1910)16.

15 Hirsch sostiene que los matrimonios interétnicos se incrementaron en los últimos años por el número reducido de los tapietes en Tartagal, lo cual no corresponde a su observación sobre las muchas parejas mixtas de ancianos.

16 Ver también Nordenskiöld, 2002 [1912]: 282. Sobre los tapietes «peones» de los blancos y los tapï a la vez, ver Combès, 2005: cap. 7. 
¿Trabajadores de los chanés (de los tapii, de los ex esclavos) sea en el Isoso o bien en el norte argentino? Todo indica que estamos ahí ante el origen del nombre mismo de los tapitiete, nombre que recién aparece, como ya lo subrayamos, en el siglo XIX. A esta situación se puede aplicar la observación de Richard:

«el término mismo es la huella de la relación tejida entre estos grupos, y sólo en este marco pudo surgir» (Richard, s/f; énfasis de origen).

\section{EL MISTERIO PARADIGMÁTICO}

Al finalizar estas líneas, son dos las conclusiones o las enseñanzas sobre las cuales quisiera insistir: la primera más localizada, la segunda extensiva a toda la etnografía y la etnohistoria del Chaco -y, ¿quién sabe?, de otras regiones más-.

Empecemos por la primera. La ya clásica tesis que explica «el nacimiento de la identidad chiriguano» (Combès \& Saignes, 1991) se basa sobre la «absorción» de los chanés por los migrantes guaraníes llegados del este, dando así nacimiento a una nueva etnia, una nueva cultura, que es la chiriguana. Esta tesis sigue siendo correcta — pero «a grandes rasgos» y «en general»—. Más que verdaderamente cuestionada, esta tesis fue relativizada en los últimos años, en dos sentidos: primero, como ya mencioné, los autores (Lowrey, 2003; Combès, 2005; 2006b; Combès \& Villar, 2004; 2007; Combès \& Lowrey, 2006) han mostrado que a la «guaranización» de los chanés correspondió una «chaneización» de los guaraníes que no se reduce a la cultura material sino que abarca, en particular, la esfera política; segundo, las investigaciones etnohistóricas han sacado a la luz la existencia, algo descuidada o ignorada por la historiografía tradicional, de verdaderos «rincones»o «núcleos» chanés en pleno territorio chiriguano, dos de los cuales (el Isoso en Bolivia y el Itiyuro en Argentina) perduran todavía hoy17. La región del río Itiyuro fue poblada por los chanés de Sanandita a finales del siglo XVIII, mediante una alianza guerrera de los chanés con los tobas y matacos en contra de los chiriguanos (Combès, 2007); la del Isoso lo fue mucho más tempranamente, a mediados del siglo XVI, y constituyó de alguna manera una suerte de escudo que protegía a los chanés que partieron «hacia el río Paraguay» como lo dijeron los isoseños a Nordenskiöld. En esta perspectiva, el Gran Chaco también aparece en cierto sentido como otro «rincón» chané: pero un rincón inmenso, impenetrable, y sobre todo un rincón donde los chanés fugitivos trabaron alianzas con los grupos autóctonos que tanto aportaron a su cultura hoy nítidamente chaqueña. Solo a partir del siglo XIX, los tap $\ddot{i}$ ñemi, los fugitivos escondidos, se vuelven, a la vez, «tapietes» porque trabajadores de los tapï, e yanaigua porque semejantes a los demás «salvajes» del Chaco.

La segunda enseñanza de esta historia reside, a mi entender, en el plural que sugiero aplicar, y con énfasis, a los tapietes. Estos grupos son el resultado — que es imposible de calificar de definitivo- de diferentes aportes que se sucedieron diacrónicamente desde la Cordillera y el Chaco (fugas de chanés guaranizados y luego de chiriguanos en diferentes épocas, es decir también con un grado diferente de adopción, por ejemplo, de las costumbres misioneras; coaliciones de grupos chaqueños en el siglo XIX) y sincrónicamente en el Chaco mismo, mediante alianzas matrimoniales e intercambios con diferentes grupos locales, chorotes, matacos, tobas o nivaklés. Si bien es inoperante la tradicional clasificación

17 Además del Isoso y del Itiyuro, los rincones chanés identificables son principalmente los de Saypurú en la Cordillera chiriguana, cuyos habitantes emigraron luego al río Acero donde los franciscanos fundaron entre ellos su primera misión en 1758, y del valle de Caipependi a orillas del río Pilcomayo. 
lingüística de las etnias en este caso, tampoco es útil una «clasificación» que solo vería en los tapietes una suma de etnias - chanés + matacos, chiriguanos + chanés + nivaklés, etc.- . El total no es (no es solamente) la suma de las partes, y este total está hecho de varias capas de sedimentación — guaranización por intermedio de chanés-, de aportes nuevos y de adaptaciones que no son ni fueron nunca fijas, sino siempre dinámicas y cambiantes. En Bolivia, la única comunidad tapiete existente hoy, la de Samuwate, se afilió en los últimos años a la organización weenhayek (mataco, wichí), para luego apegarse a la organización «guaraní» (chiriguana) y volver luego con los weenhayeks — siempre con problemas, siempre confrontada a una sola mitad de su historia-. El «misterio» tapiete no es solo un misterio: es, ciertamente, paradigmático de toda la dinámica étnica chaqueña y de su periferia que los investigadores necesitamos volver a pensar, con nuevas herramientas conceptuales o teóricas. El mapa étnico actual del Chaco, con los etnónimos que hoy conocemos y son tantas etiquetas que «fijan» o reifican una «etnia», es el resultado, reciente, de la desarticulación de las redes interétnicas provocada por la guerra del Chaco (19321935) y una nueva articulación construida en los marcos nacionales y estatales bolivianos, paraguayos y argentinos (ver Richard, 2008). En otras palabras, y si de etnohistoria se trata, la situación actual no debe enceguecer al investigador ni imponerle un marco que resulta totalmente inoperante para entender $-\mathrm{O}$ al menos intentar entender - la antigua Babel chaqueña 18.

El «caso» tapiete es paradigmático de los «cambios transétnicos» (Santos-Granero, 2002: 48) o de los procesos de «etnogénesis» tales como los enfocan trabajos recientes, dejando de lado las antiguas cargas negativas de los conceptos de «aculturación» a favor de un énfasis sobre los procesos creativos de adaptación19; es paradigmático de la discusión, siempre abierta, sobre las problemáticas relaciones entre lengua y cultura (ver Whitehead, 2002: 72; Julien, 2007; Combès, 2005: 331); invita a repensar los procesos de etnogénesis en términos más complejos que la simple difusión de artefactos, costumbres o rasgos culturales (Hornborg, 2005: 607).

A estos procesos bien se podría aplicar la frase que Lavoisier volvió célebre — «nada se pierde, nada se crea, todo se transforma»—. Y todo se transforma, quisiera insistir sobre este punto, en el tiempo, es decir en la historia. Los yanaiguas del siglo XIX que asaltan el Isoso no son los mismos que los chanés que huyeron Chaco adentro en el siglo XVI y tampoco los mismos que los actuales «tapietes» — quienes además no apelan todos a este nombre-. Existe tanta distancia y diferencia - tanta historia - entre ellos como entre los italianos de hoy y los romanos de Julio César. Sin embargo, y si bien a nadie se le ocurriría escribir «la historia de los italianos en los tiempos de César» o algo tan absurdo como la historia de los argentinos en el siglo XII, el reparo aparentemente no es el mismo cuando de indios se trata. Quedándonos en el ámbito chaqueño o en su periferia, un par de ejemplos bastará. Birgit Krekeler (1995) escribe «la historia de los chiquitanos» empezando desde el siglo XVI — cuando «los chiquitanos» solo surgen en la literatura en el siglo XX y cuando sus inmediatos antecesores «los chiquitos» son el producto de la reunión de grupos de origen totalmente diversos (arawak, bororó-otuqui, zamuco, etc.) en las misiones jesuíticas del siglo XVIII—; más recientemente, Volker von Bremen (2007) evoca la historia de los «zamucos/ ayoréode» durante la guerra del Chaco (1932-1935) — cuando los «zamucos» pertenecen

18 Sobre la necesidad de una «relectura» de la historia étnica colonial y precolonial del Chaco y su periferia, remito a Combès, 2006c.

19 Ver en particular Hill \& Santos-Granero, 2002; Hornborg, 2005; Hill, 1996. 
a la literatura del siglo XVIII y los «ayoréode» recién aparecen como tales en los años 1950 - Se rastrea, en suma, «la historia de la etnia» y poco importan esos cambios súbitos de nombres o de ubicación que, al parecer, no alteran la esencia profunda e inamovible de «la etnia». Como lo subraya un muy reciente y muy sugestivo texto, estas investigaciones postulan «una entidad perenne cuyas huellas habrían que seguir, no para mostrar ajustes y recomposiciones, procesos y evoluciones, sino para confirmar su milenaria existencia» (Richard, 2008: 133). Pretendiendo «hacer historia», adoptan sin embargo una concepción demasiado estática, demasiado «ilusoria» (Hornborg, 2005: 607), demasiado a-histórica en suma de lo que puede «ser» un pueblo; una concepción demasiado esencialista también, en la cual intercambios, interacciones, préstamos, contactos, trueques y alianzas pasan de largo sin afectar la «milenaria identidad» del grupo: «límites de una «etnohistoria» que hace la historia de las etnias sin interrogarse sobre su historicidad» (Richard, 2008: 95); límites de un enfoque que al rastrear su pasado empuja a las etnias fuera de su historia.

De alguna manera, los párrafos que anteceden no hicieron más que desarrollar algunas de las intuiciones de Branislava Susnik y de las observaciones pioneras de Gustavo González sobre los «guaraní-chané o ñanaguas» que son los inclasificables tapietes. Queda por esperar que estas líneas no solo habrán contribuido a resolver «el apasionante enigma etnográfico» de los tapietes, sino también ayuden a comprender que el «misterio» solo existió, en gran medida, por las maneras y las herramientas utilizadas para pensarlo.

\section{Referencias citadas}

\section{Fuentes primarias}

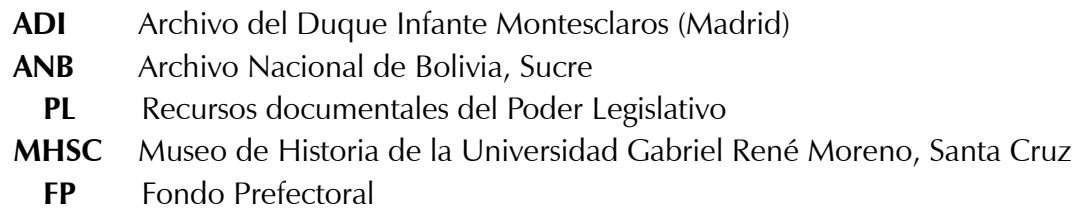

\section{Fuentes secundarias}

ANNUA..., 1965 [1596] - Annua de la Compañía de Jesús - Tucumán y Perú. In: Relaciones geográficas de Indias II (Marco Jiménez de la Espada, ed.): 86-113; Madrid: Ediciones Atlas. Biblioteca de Autores Españoles, t. 184.

ANÓNIMO, 1941 [c. 1573] - Descripción del río de La Plata. In: Documentos históricos y geográficos relativos a la conquista y colonización rioplatenses (José Torre Revello, ed.): t. 1: 65-68; Buenos Aires: talleres Casa J. Peuser.

ARCE, E., GUTIÉRREZ, R., GUTIÉRREZ, I. \& VÉLIZ, R., 2003 - Estrategias de sobrevivencia entre los tapietes del Gran Chaco, 206 p.; La Paz: PIEB.

AUDIENCIA DE CHARCAS, 1922 [1566] - Carta al lic. Castro, La Plata 10-06-1566. In: La Audiencia de Charcas. Correspondencia de presidentes y oidores (Roberto Levillier, ed.): t. II: 437-456, Madrid: Colección de publicaciones históricas de la biblioteca del Congreso argentino. 
AYOROA, A., 1927 - Una interesante exploración al interior del Chaco. Revista militar, s/n: 513-529; La Paz.

BARZANA, A. de, 1965 [1594] - Carta al P. Juan Sebastián, Asunción 1594. In: Relaciones geográficas de Indias II (Marco Jiménez de la Espada, ed.): 78-85; Madrid: Ediciones Atlas. Biblioteca de Autores Españoles, t. 184.

CALIFANO, M., 1978 - Los tapui: un enigma etnográfico. Cuadernos Franciscanos, 49: 169-188.

CAMPOS, D., 1888 - De Tarija a la Asunción. Expedición boliviana de 1883, 785 p.; Buenos Aires: Jacobo Peuser.

CARDÚS, J., 1886 - Las misiones franciscanas entre los infieles de Bolivia. Descripción del estado de ellas en 1883 y 1884, 429 p.; Barcelona: lib. de la Inmaculada Concepción.

CARVAJAL, S., 1998 - Etnohistoria y ocupación espacial del pueblo tapiete. In: Anales de la reunión anual de etnología, t. 1: 363-385.

CHOMÉ, I., 1791 [1738] - Quatrième lettre du P. Ignace Chomé, San Ignacio de Zamucos, 17-05-1738. In: Lettres édifiantes et curieuses écrites des missions étrangères, t. 8: 125-128; París: Mérigot le Jeune.

CLASTRES, H., 1972 - Les beaux-frères ennemis : à propos du cannibalisme tupinamba. Nouvelle Revue de Psychanalyse, 6: 71-82.

COMBÈS, I., 2004 - Tras la huella de los ñanaigua: de tapii, tapiete y otros salvajes en el Chaco boliviano. Bulletin de I'Institut Français d'Études Andines, 33 (2): 255-269.

COMBÈS, I., 2005 - Etno-historias del Isoso. Chané y chiriguanos en el Chaco boliviano (siglos XVI a XX), 396 p.; La Paz: IFEA/PIEB.

COMBÈS, I., 2006a - Cuando el nombre no hace al indio. In: Definiciones étnicas, organización social y estrategias políticas en el Chaco y la Chiquitania (Isabelle Combès, ed.): 19-23; Santa Cruz: IFEA/SNV/Editorial El País.

COMBÈS, I., 2006b - Chané perversos y chiriguanos canonizables. Ponencia presentada en el Simposio «Liderazgo, representatividad y control social en el Gran Chaco Sudamericano y zonas adyacentes»; Resistencia, agosto de 2006.

COMBÈS, I., 2006c - Coçi: hacia una relectura de la historia del oriente boliviano. In: Definiciones étnicas, organización social y estrategias políticas en el Chaco y la Chiquitania (Isabelle Combès, ed.): 69-79; Santa Cruz: IFEA/SNV/Editorial El País.

COMBÈS, I., 2007 - De Sanandita al Itiyuro: chané, chiriguano (iy tapiete?) al sur del Pilcomayo. Indiana, 24: 259-289.

COMBÈS, I. \& HIRTZEL, V., 2007 - Apuntes sobre los tamacocis. Anuario de estudios bolivianos, archivísticos y bibliográficos, 13: 239-268; Sucre.

COMBÈS, I. \& LOWREY, K., 2006 - Slaves without masters? Arawakan dynasties among the Chiriguano (Bolivian Chaco, XVI-XX centuries). Ethnohistory, 53 (4): 689-714.

COMBÈS, I. \& SAIGNES, T., 1991 - Alter Ego. Naissance de I'identité chiriguano, 152 p.; París: EHESS/Cahiers de l'Homme.

COMBÈS, I. \& VILLAR, D., 2004 - Aristocracias chané. «Casas` en el Chaco argentino y boliviano. Journal de la Société des Américanistes, 90/2: 63-102.

COMBÈS, I. \& VILLAR, D., 2007 - Os mestiços mais puros. Representaçoes chiriguano e chané da mestiçagem. Mana, 13 (1): 41-62.

CRÓNICA ANÓNIMA, 1944 [c. 1600] - Crónica anónima. In: Historia General de la Compañía de Jesús en la provincia del Perú (P. Mateos, ed.): 471-507; Madrid: s/ed.

DÍAZ DE GUZMÁN, R., 1835 [1612] - Historia argentina del descubrimiento, población y conquista de las provincias del río de la Plata. In: Colección de obras y documentos relativos a la historia antigua y moderna de las provincias del río de la Plata (Pedro de Angelis, ed.): t. 1: 1-156; Buenos Aires: imprenta del Estado. 
DÍAZ DE GUZMÁN, R., 1979 [1618] - Relación de la entrada a los Chiriguanos, 173 p.; Santa Cruz: Fundación cultural «Ramón Darío Gutiérrez».

DIETRICH, W., 1986 - El idioma chiriguano, 356 p.; Madrid: Instituto de Cooperación Iberoamericana, ed. Cultura Hispánica.

ESTIVAL, J.-P., 2002 - Culture et consommation dans une communauté guarani-ñandeva du Chaco. Techniques et culture, $\mathbf{3 8}$ <http://tc.revues.org/document1276.html >

FAUSTO, C., 2003 - Masks, trophies and spirits: making invisible relations visible. Ponencia presentada en el $51^{\circ}$ Congreso Internacional de los Americanistas, Santiago de Chile.

GIANELLI, J., 1988 [1863] - Relación original de las expediciones del Pilcomayo del año 1863. In: Historia de Tarija (Corpus documental). Tomo V (Erick Langer \& Zulema Bass Werner de Ruíz, eds.): 289-303; Tarija: Universidad Autonóma «Juan Miseal Saracho».

GIANNECCHINI, D., 1896 - Diario de la expedición exploradora boliviana al Alto Paraguay de 1886-1887, 359 p.; Asís: Tip. de la Porciúncula.

GIANNECCHINI, D., 1988 [1879] - Apuntes originales de la historia de las misiones de 1874 a 1879. In: Historia de Tarija (Corpus documental). Tomo V (Erick Langer \& Zulema Bass Werner de Ruíz, eds.): 320-333; Tarija: Universidad Autonóma «Juan Miseal Saracho».

GIANNECCHINI, D., ROMANO, S. \& CATTUNAR, H., 1916 - Diccionario chiriguano/ español y español/chiriguano, 2 t., 256 y 190 pp.; Tarija: s/ed.

GONZÁLEZ, G., 1968 - Entre los Guaraní-Chané (o Ñanaguas) del Noroeste chaqueño. Suplemento antropológico de la revista del Ateneo paraguayo, III/1-2: 259-338.

GONZÁLEZ MALDONADO, R., 1965 [C. 1564] - Relación atribuida a Ruy González Maldonado. In: Relaciones geográficas de Indias I (Marco Jiménez de la Espada, ed.): 398-401; Madrid: Ediciones Atlas. Biblioteca de Autores Españoles, t. 183.

HILL, J., 1996 - Introduction: Ethnogenesis in the Americas, 1492-1992. In: History, Power and Identity: Ethnogenesis in the Americas 1492-1992 (Jonathan Hill, ed.): 1-19; lowa City: University of lowa Press.

HILL, J. \& SANTOS-GRANERO, F. (eds.), 2002 - Comparative Arawakan Histories. Rethinking Language Family and Culture Area in Amazonia, 340 p.; Urbana: University of Illinois Press.

HIRSCH, S., 2006 - El pueblo tapiete de Argentina: historia y cultura, 143 p.; Buenos Aires: Instituto de Lingüística, Facultad de Filosofía y Letras, Universidad de Buenos Aires.

HORNBORG, A., 2005 - Ethnogenesis, Regional Integration and Ecology in Prehistoric Amazonia. Toward a System Perspective. Current Anthropology, 46 (4): 589-620.

LIZÁRRAGA, R. de, 1968 [c. 1600] - Descripción breve de toda la tierra del Perú, Tucumán, Río de la Plata y Chile, 213 p.; Madrid: Ediciones Atlas. Biblioteca de Autores Españoles, t. 216.

JOFRÉ, M. O., 2006 [1895] - Colonias y misiones. Informes de la visita practicada por el delegado del Supremo Gobierno. In: Presencia franciscana y formación intercultural en el sudeste de Bolivia según documentos del archivo franciscano de Tarija 1606-1936, t. IV (Lorenzo Calzavarini, ed.): 453-533; Tarija: Centro Eclesial de Documentación.

JULIEN, C., 2007 - Kandire in Real Time and Space: Sixteenth-Century Expeditions from the Pantanal to the Andes. Ethnohistory, 54 (2): 245-272.

KREKELER, B., 1995 - Historia de los chiquitanos, 239 p.; Santa Cruz: APCOB. 
LOWREY, K., 2003 - Enchanted ecology: magic, science and nature in the Bolivian Chaco, 406 р.; Chicago: University of Chicago. Ph-D thesis of anthropology.

LOZANO, P., 1733 - Descripción chorográfica (...) del Gran Chaco Gualamba, 466 p.; Córdoba: Colegio de la Asunción.

MATIENZO, J. de, 1922 [1561] - Carta a S. M., La Plata 20-10-1561. In: La Audiencia de Charcas. Correspondencia de presidentes y oidores (Roberto Levillier, ed.): t. 1: 5460; Madrid: Colección de publicaciones históricas de la biblioteca del Congreso argentino.

MARTARELLI, A. \& NINO, B. de, 2006 [1918] - El Colegio franciscano de Potosí y sus misiones en el Chaco. Noticias históricas recogidas por dos misioneros del mismo Colegio, 524 p.; Cochabamba: talleres gráficos Kipus.

MÉTRAUX, A., 1946 - Ethnography of the Chaco. In: Handbook of South American Indians 1 (Julian Steward, ed.): 197-370; Wasington: Smithsonian Institution.

NINO, B. de, 1912 - Etnografía chiriguana, 332 p.; La Paz: tip. comercial I. Argote.

NORDENSKIÖLD, E., 1910 - Sind die Tapiete ein guaranisienter Chacostamm? Globus, XCVIII: 181-186.

NORDENSKIÖLD, E., 2001 [1924] - Exploraciones y aventuras en Sudamérica, 438 p.; La Paz: APCOB/Plural.

NORDENSKIÖLD, E., 2002 [1912] - La vida de los indios. El Gran Chaco (Sudamérica), 312 p.; La Paz: APCOB/Plural.

PIFARRÉ, F., 1989 - Los Guaraní-Chiriguanos 2. Historia de un pueblo, 542 p.; La Paz: CIPCA.

RICHARD, N., s/f - De l'ethnonyme à l'anthroponyme dans le Chaco paraguayen: les politiques du nom (inédito).

RICHARD, N., 2008 - Les chiens, les hommes et les étrangers furieux. Archéologie des identités indiennes dans le Chaco boréal, 713 p.; París: EHESS. Thèse de doctorat en anthropologie.

RUIZ DE MONTOYA, A., 1876 [1640] - Tesoro de la lengua Guaraní o más bien Tupí, 407 ff.; París: Maisonneuve \& Co.

SANABRIA, H., 1972 - Apiaguaiqui-Tumpa. Biografía del pueblo chiriguano y de su último caudillo, 245 p.; La Paz/Cochabamba: los Amigos del Libro.

SANABRIA, H., 1988 [1958] - En busca de Eldorado. La colonización del oriente boliviano, 288 p.; La Paz: Juventud.

SÁNCHEZ LABRADOR, J., 1910 [c. 1767] - El Paraguay católico, 2 t.: 323 y 332 pp.; Buenos Aires: imprenta de Coni Hermanos.

SANTOS-GRANERO, F., 2002 - The arawakan matrix: ethos, language and history in native South America. In: Comparative Arawakan histories. Rethinking languages family and cultural area in Amazonia (Jonathan Hill \& Fernando Santos Granero, eds.): 25-50; Urbana: Univ. of Illinois Press.

SCHMIDT, M., 1937 - Los tapietés. Revista de la sociedad científica del Paraguay, IV (2): 36-67.

SUÁREZ DE FIGUEROA, L., 1965 [1586] - Relación de la ciudad de Santa Cruz de la Sierra. In: Relaciones geográficas de Indias I (Marco Jiménez de la Espada, ed.): 402406; Madrid: Ediciones Atlas. Biblioteca de Autores Españoles, t. 183.

SUSNIK, B., 1968 - Chiriguanos I. Dimensiones etnosociales, 269 p.; Asunción: Museo etnográfico Andrés Barbero.

SUSNIK, B., 1989 - Etnohistoria del Paraguay. América Indígena, XLIX-3: 431-490. 
Los fugitivos escondidos. Acerca del enigma tapiete

VILLAR, D., 2006 - La religión chané, 243 p.; Buenos Aires: Universidad de Buenos Aires. Tesis de doctorado en filosofía y letras.

VON BREMEN, V., 2007 - Impactos de la guerra del Chaco en la territorialidad ayorea. In: Les guerres du Paraguay aux XIXe et XXe siècles (Nicolas Richard, Luc Capdevila \& Capucine Boidin, eds.): 263-280; París: Colibris.

WHITEHEAD, N., 2002 - Arawak Linguistic and Cultural Identity through Time: Contact, Colonialism, and Creolization. In: Comparative Arawakan histories. Rethinking languages family and cultural area in Amazonia (Jonathan Hill \& Fernando Santos Granero, eds.): 51-73; Urbana: Univ. of Illinois Press. 